\title{
Caesarean Section in Confirmed COVID-19 Patient at Nepalgunj Medical College: Case Report
}

\author{
Sinha $\mathrm{K}^{1}$, Kushwaha $\mathrm{A}^{1}$, Adhikari $\mathrm{H}^{1}$
}

\section{ABSTRACT}

An outbreak of novel coronavirus pneumonia occurred worldwide since December 2019, which had been named COVID-19 subsequently. It is extremely transmissive that infection in pregnant women were unavoidable. The delivery process will produce large amount of contaminated media, leaving a challenge for medical personnel to ensure both the safety of the mother and infant and good self-protection. Here, we report a 27 year woman had reverse transcription polymerase chain reaction-confirmed COVID-19 at 37 weeks 2 days of gestation. An emergency caesarean section at 38 weeks 2 days of gestation under spinal anaesthesia was performed for oligohydramnios with scar tenderness with strict protection for all personnel.

\section{Keywords: Covid-19, Pregnancy, SARS-cov-2}

\section{Authors:}

1. Dr. Kavita Sinha

2. Dr. Amrendra Kushwaha

3. Dr. Homnath Adhikari

${ }^{1}$ Department of Obstetrics \& Gynaecology, Nepalgunj Medical College and Teaching Hospital, Kohalpur, Banke

\section{Address for Correspondence:}

Dr. Kavita Sinha

Department of Obstetrics \& Gynaecology

Nepalgunj Medical College and Teaching Hospital

Kohalpur, Banke, Nepal

Email: ksinhapandey@gmail.com

\section{INTRODUCTION}

Coronavirus diseases 2019 (COVID-19) is a new pathology declared a public health emergency by the World Health organization, which can have negative consequences for pregnant women and their newborns. In early December 2019, a cluster of cases of pneumonia of a newly identified corona virus was noted in Wuhan in china. ${ }^{1}$ The corona virus was initially termed 2019-ncovV and subsequently SARS-COV-2, producing a diseases that had been termed COVID $-19 .{ }^{2}$ SARS-COV-2 can be transmitted through small droplets from normal breathing, coughing and sneezing, and by aerosol or fluid from human secretion or discharges. ${ }^{3,4,5}$ Patients of mild COVID-19 may present with fever, fatigue, dry cough, but severe infection may progress rapidly to acute respiratory distress syndrome, septic shock, intractable acidosis and coagulopathy. ${ }^{6}$ Pregnant women infected with SARS-COV-2 were at high risk of developing severe pneumonia, heart failure and other complications which could be life threatening leading to death in many cases. Here, we report a COVID-19-confirmed case of pregnancy with oligohydramnios and previous caesarean section. Ethical clearance was obtained from Institutional review committee, Nepalgunj Medical College.

\section{CASE REPORT}

This patient consented to publication of the case and signed written informed consent. A 27years, Gravida 3, Para 2 women $(145 \mathrm{~cm}, 45 \mathrm{~kg})$ with previous caesarean section who had Reverse transcription polymerase chain reaction (RT-PCR) confirmed COVID-19 at 37 weeks 2 days of gestation. She was at quarantine as had a travel history to endemic area. Her PCR was positive on $22^{\text {nd }}$ day after returning from endemic region. She was referred as per the government guidelines to our hospital from a hospital located $250 \mathrm{~km}$ away for the possible need of caesarean section. Nepalgunj Medical College and Teaching Hospital has been designed as level III tertiary hospital by government of Nepal, for serving the COVID positive patients requiring multispecialty services.

On examination her general condition was fair, uterus 34 weeks size, longitudinal lie, cephalic presentation, scar tenderness present, FHR 140 beats per minute; per vaginal examination showed Os parous, uneffaced, soft, central with show present. The laboratory test results showed a leukocyte count 9,300 cells $/ \mathrm{mm}^{3}$ with Neutrophil $76 \%$ and lymphocyte $21 \%$. Ultrasound examination showed placenta grade III with amniotic fluid index 5 . Hence, planned for caesarean section.

The patient wearing a surgical facemask and lying in stretcher was sent through a designated channel to Negative pressure operating room. All participants equipped with personnel protective equipment performed an emergency section at 38 weeks 2 days of gestation under spinal anaesthesia. The caesarean section was performed uneventfully. The neonate was $2400 \mathrm{~g}$, with Apgar score at 1 and $5 \mathrm{~min}$ of 6 and 8 , respectively.

The patient referred back to the isolated postoperative ward accompanied by the attending anaesthesiologist after surgery. Both of them were discharged smoothly at day 7 postoperatively after SARS-CoV-2 detection of maternal and neonatal nasopharyngeal swab specimen turned negative. 
All the surgical participants were directed to quarantine area following a planned route after the caesarean section. RT-PCR of all the involved health care workers taken on $7^{\text {th }}$ day after the last exposure were negative.

\section{DISCUSSION}

We performed an emergency caesarean section in a patient with a highly infectious respiratory viral pathogenic disease. The multidisciplinary team worked together to formulate detailed plans and made sufficient preparations, which lead an uneventful outcome of the mother, the newborn, and all heath care workers. However, there are few reports available for reference on exact anaesthesia design for pregnant women confirmed with COVID-19. ${ }^{7}$

COVID-19 spreads very rapidly. It was declared a global pandemic by WHO, which neither previous SARS nor MERS could be considered. ${ }^{8}$ It might transmit through droplets, contact and respiratory aerosols within $<6$ feet range during the caesarean section. ${ }^{9}$

\section{CONCLUSION}

Confronted with a caesarean section which owns a high risk of infection, a thorough anaesthesia plan, and a multidisciplinary cooperation can improve the safety of mothers and infants, and reduce the risk of infection of medical staff, conducive to epidemic prevention and control.

\section{REFERENCES}

1. Zhu N, Zhang D, Wang W. A novel coronavirus from patients with pneumonia in China, 2019. N Engl J Med. 2020;382(8):727-733. doi: 10.1056/NEJMoa2001017.

2. Geneva S. WHO Director-General's remarks at the media briefing on 2019-nCoV on 11 February 2020. https://www.who.int/dg/ speeches/detail/who-director-general-s-remarks-at-the-mediabriefing-on-2019-ncov-on-11-february-2020. Accessed 12 Feb 2020.

3. Huang C., Wang Y., Li X. Clinical features of patients infected with 2019 novel coronavirus in Wuhan, China. Lancet. 2020 doi: 10.1016/S0140-6736(20)30183-5. Advance Access published online January 24.

4. Wang D., Hu B., Hu C. Clinical characteristics of 138 hospitalized patients with 2019 novel coronavirus-infected pneumonia in Wuhan, China. JAMA. 2020 doi: 10.1001/jama.2020.1585. Advance Access published on February 7.

5. Li Q., Guan X., Wu P. Early transmission dynamics in Wuhan, China, of novel coronavirus-infected pneumonia. N Engl J Med. 2020 doi: 10.1056/NEJMoa2001316. Advance Access published on January 29.

6. Huang C, Wang Y, Li X. Clinical features of patients infected with 2019 novel coronavirus in Wuhan. China Lancet. 2020;395(10223):497506. doi: 10.1016/S0140-6736(20)30183-5.
7. Xia H, Zhao S, Wu Z, Luo H, Zhou C, Chen X. Emergency caesarean delivery in a patient with confirmed coronavirus disease 2019 under spinal anaesthesia. Br J Anaesth. 2020;124(5):e216-e218. doi: 10.1016/j.bja.2020.02.016.

8. Geneva S. WHO Director-General's opening remarks at the media briefing on COVID-19-11 March 2020. https://www. who.int/dg/speeches/detail/who-director-general-s-openingremarks-at-the-media-briefing-on-covid-19---11-march-2020. Accessed 11 Mar 2020.

9. Li Q, Guan X, Wu P. Early transmission dynamics in wuhan, China, of novel coronavirus-infected pneumonia. N Engl J Med. 2020;382(13):1199-1207. doi: 10.1056/NEJMoa2001316. 